Sarmad S Al-Kassar BDS, MSc (Asst. Lec.)

\section{The Force Degradation of Elastic Chain in Different Environments and for Different Intervals (An In Vitro Study)}

\author{
Dept of Pedod, orthod, and Prev Dentistry \\ College of Dentistry, University of Mosul.
}

\begin{abstract}
Aims: This study designed to determine the force degradation of elastomeric chains (Dentaurum) at different time intervals in different media (air, distill water, Biofresh mouth wash and artificial saliva) and to compare the effect of wet and dry conditions on the force relaxation. Materials and methods: forty new modules of elastomeric chain of sex loops length divided into 4 main groups according to the environment (air, distill water, Biofresh mouth wash "F" and artificial saliva $\mathrm{pH}$ 6.75)and stored in an incubator at $37^{\circ} \mathrm{C}$, Mean load were recorded for the samples at each time interval zero, 1,24 hour and 1 and 3 weeks respectively, the load measurement were done by tensile testing machine with use of special fixture to hold the samples and stretched over special framework. Results: The results showed that the mean percent force remaining of elastics is affected by stretching, water absorption, chemicals and times and the amount of loss in dry is less than in wet environments and especially in biofresh mouth wash more than the neutral saliva. Conclusions: the elastomeric chains are greatly affected by stretching, moisture and time.
\end{abstract}

Key wards: force degradation, elastic chain, mouth rinse.

Al-Kassar SS. The Force Degradation Of Elastic Chain In Different Environments And For Different Intervals (An In Vitro Study). Al-Rafidain Dent J. 2011; 11(2):231-237.

Received: 12/11/2008 Sent to Referees: 13/11/2008

Accepted for Publication: 5/4/2009

\section{INTRODUCTION}

The orthodontist must plan how to close any space that is not devoted to relief of crowding; whether anterior retraction, posterior protraction, or a combination of both. ${ }^{(1,2)}$ Closure of spaces in the dental arch can be done with a variety of traction aids, like closed coil springs, elastomeric chain and other methods. However, force loss over time has been documented among most types of traction aids currently available 3 In oral cavity, many factors can affect on force production and force degradation of traction aids, such as saliva, temperature fluctuation, ${ }^{(1)} \mathrm{pH}$ variation, ${ }^{(3)}$,fluoride ions and rinses, ${ }^{(3)}$ oxygen content ${ }^{(4)}$,free radicals, ${ }^{(5)}$ salivary enzymes and masticatory forces. ${ }^{(6)}$ This force loss makes it difficult for orthodontists to determine the actual force transmitted to dentition. ${ }^{(7,10,27)}$ From many years ago since about 1800 s and elastomeric materials used in dental practices, they are used to produce force form many uses may be dental or skeletal. ${ }^{(5)}$ Elastomeric chains were introduced to the orthodontic profession in the 1960s, and are now an integral part of many practices, and largely replaced latex elastics for intra-arch tooth movement. ${ }^{(5)}$ The elastomers are amorphous, cross-linked polymers that have number of bridges between the linear molecules that form a three-dimensional network which at rest tend to be distributed at random, irregular pattern of folded linear molecular chain which holed each other by van der waals (secondary bonds). ${ }^{(6)}$ Elastomeric chain are economical and easy to use though they absorb water and saliva, permanently stain and suffer of breakdown of internal bonds, that lead to permanent deformation. Also, elastomeric chain undergoes stress relaxation (degradation), which is a decrease in the magnitude of force transmitted while held at a fix strain. This relaxation is in part due to rearrangement within the polymer structure. ${ }^{(34)}$ Eliades et al ${ }^{(16)}$ state that the mechanism of permanent deformation of polymeric materials include molecular chain stretching, slippage between adjacent molecular chain, and molecular chain scission. During stretching, the material is subject to an instantaneous elastic deformation. As the 
load is maintained, there is retarded elastic deformation, as well as an irreversible viscous deformation, producing permanent elongation (depending on the load). During unloading, the instantaneous elastic strain is immediately recovered, followed by a decay of the retarded elastic strain. The term "creep compliance"encompasses all three aspects, the instantaneous elastic deformation, the retarded elastic deformation, and the permanent deformation. ${ }^{(13)}$ The use of chlorhexidine mouth rinse has become more popular especially at the first four to eight weeks of orthodontic therapy. Because plaque control in the early stages of orthodontic appliance therapy may be compromised and chlorhexidine can be prescribed for that reason. ${ }^{(36)}$ The aims of this study is to determine the force produced and force degradation of elastomeric chains (Dentaurum) at different time intervals in different media (air, distilled water, Biofresh mouth wash and artificial saliva) and to compare the effect of wet and dry conditions on the force relaxation.

\section{MATERIALS AND METHODS}

The samples were forty new modules of elastomeric chain of six loops length with an extra-half loop was allowed at the two ends of the sample to prevent distortion while cutting of the chain. These samples were divided into four main groups according to the media (air, distilled water, Biofresh mouth wash "F" and artificial saliva), 10 samples for each, $\mathrm{pH}$ of artificial saliva was $6.75 \pm 0.15$. The water and artificial saliva were changed every two days throughout study and were kept in covered glass containers to prevent evaporation and consequent $\mathrm{pH}$ changes. All samples were stored in an incubator at $37^{\circ} \mathrm{C}$ to resemble body temperature and held in air at room temperature $\left(30-35^{\circ} \mathrm{C}\right)$ throughout measuring period. Mean load were recorded for the samples at each time interval zero, 1, 24 hour and 1 and 3 weeks respectively for a total of 200 measurements. Every chain was stretched between two hooks from the u-beams were prepared according to Ferriter et $a l^{(19)}$ as showed in the figure.

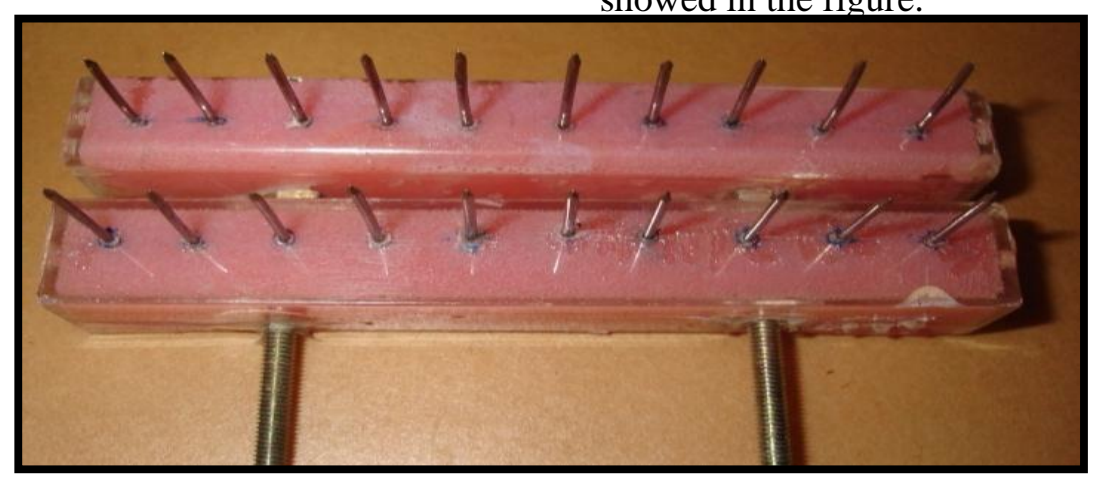

Figure : The U Shape Acrylic Block

The lengths of extensions of traction aids samples are chosen so that each sample will produce a $(200 \pm 5) \mathrm{gm}$ force at that extension, this force used by study of Bousquet et al, this force range are considered a force within physiological limit. ${ }^{(3,31)}$ The method of determining the sample extension length in a relation to a specific force value produced by that extension, was used by Ferriter et al. Each fixture consists of metallic ruler (with milimeter graduation), the ruler was cut in (L) shape. A stainless steel pin was soldered to the middle of the $(\mathrm{L})$ shaped ruler in a horizontal direction. This ruler was attached in an upper clamp in the universal tensile testing machine. A similar ruler was pre- pared in the same manner and attached in the lower clamp in the machine. The purpose of these fixtures was for attachment of samples in the tensile testing machine to measure force production. After that, the sample returns back to its place in channels with the aid of tucker and this procedure was repeated for all samples and at every time intervals. Channels were initially adjusted to permit stretching of elastic chains to the predetermined distance including air, Distall water, biofresh mouth wash ' $F$ ' and artificial saliva but later were reduced (simulating tooth movement) at rate of $0.5 \mathrm{~mm}$ per two weeks by a screw threaded mechanism (studs) to simulate tooth movement. The 
blocks removed from saliva solution and immersed inside mouthwash solution (Biofresh 'F') which present inside glass containers and stored inside the same incubator at $37^{\circ} \mathrm{C}$. The immersion period inside mouthwash solution was for two minutes ${ }^{(11)}$ twice daily for three weeks. After the end of two minute immersion period; the loaded blocks were returned to artificial saliva container (at $37^{\circ} \mathrm{C}$ ) until next mouth wash immersion period. The term "initial force" was reserved for the force values recorded during the first stretch of the material when taken from the manufacturer's envelopes, i.e., the material was not manipulated before being stretched. ${ }^{(11)}$ From the initial force (IF) value the percentage of force degradation (FD) can be obtained according to the following equation ${ }^{(21)}$ :

$\% \mathrm{FD}=100 \times[(\mathrm{IF}-\mathrm{Ft}) / \mathrm{IF}] \ldots$ Where:

$\mathrm{IF}=$ initial force.

$\mathrm{Ft}=$ force at specific period of time.

Descriptive Statistics, one way ANOVA tests and Duncan multiple range tests are used to measure the amounts of force Production and Force Degradation of Elastic Chain in All Incubation Media And At four Time Intervals.

\section{RESULTS AND DISCUSSIONS}

It is clear from Table 1; the force decay was increased with respect to time intervals for the elastic chain and at different environments, and illustrated a higher percentage of force loss in elastics incubated in biofresh and artificial saliva than those in air. This finding in agreement with Al-Ghazi ${ }^{(1)}$. ANOVA test (Table 1) showed statistical significant differences in mean percent force remaining at each time interval of follow up from one media to another in each company. Then Duncan's multiple analysis range test was done for each media in mean percent force remaining at each time interval of follow up and showed statistical significant differences for all groups (Table 2) The force decay in distilled water, biofresh and artificial saliva was more than in dry media due to stretching effect and water sorption by leaching out of some element from elastic after immersion in water due to its susceptibility to hydrolysis ${ }^{(29)}$ also water molecules may act as plasticizers and negatively affect the intermolecular attraction forces of the chains of elastomers ${ }^{(22)}$.The water cause swelling of elastic due to filling of the voids in the rubber matrix by fluids lead to microstructure cracks with consequent breakdown in the intermolecular bond leads to loss of force delivered. ${ }^{(17)}$ Further more, force decay in artificial saliva was more than in distilled water because it contains many chemicals that probably change properties of elastomeric chain and associated with deformation, force degradation and relaxation behavior. Urea which is present in artificial saliva has a great negative effect on polyurethane cross linkage because it has the ability to attack bond between the $\mathrm{NH}$ and $\mathrm{C}$ which lead to weaken the elastomers. ${ }^{(9)}$

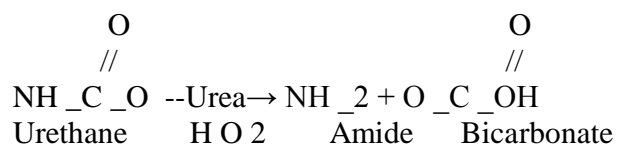

While in dry media, the force decay was due to the of stretching only because this make uncoiled chain to slip past each other and these chains held by secondary bonds which are weak and can not withstand the stretching so rupture of these bonds lead to decrease in force delivered since only stretched chain can carry load. The number of the ruptured chain increased with time and end with broken of the primary bonds and appearance of permanent deformation which manifested as a decrease in the constancy of the force. Since, long duration storage of elastomeric chains in water was found to be substantially increased in force decay rate. ${ }^{(1,6,20)}$ The force degradation of elastic chain in biofresh solution more than others this could be due to fluoride ions which present in mouthwash solution may have role in degradation process, Von Frounhofer et $a l^{(34)}$ state that exposure of Elastic Chain to topical fluoride affect the elastic properties of EC and increase the distraction of EC required to deliver initial force. Chlorhexidin present in mouthwash solution may also play a role in increasing the degradation of elastomers, Evangelista et $a l^{(18)}$ suggest that the aqueous component or the chemical substance in the disinfectant solution may plasticize or cause disruption of the intermolecular bonds and 
degradation of the elastomers. They also mentioned that in the process of storing elastomers in solution, water gets incorporated into the polymer, both water and detergents have a plasticizing effect on most polymers, which causes the polymeric chains to slip past each other, especially under load. The combination of the detergent and water would be an especially potent plasticizer. The non significance difference between effect of mouth wash solution and artificial saliva of normal $\mathrm{pH}$ may be due to short period of immersion in mouth wash (two minutes) that was not enough to show different effect from artificial saliva of normal $\mathrm{pH}$. The smallest Force Degradation percent among all media and time experienced was shown in Elastic Chain samples present in dry condition and tested after 1 hour after extension. The mechanism of permanent deformation and rearrangement within the polymer structure, effect of air and effects of free radical generating systems (ozone and ultraviolet light) might be the cause of Force Degradation in dry condition after 1 hour. ${ }^{(7,10,13,15,20,23,30,34,35)}$

Table (1): Descriptive Statistics and Duncan's Test Of Force Production And Force Degradation Of Elastic Chain In All Incubation Media And At four Time Intervals.

\begin{tabular}{|c|c|c|c|c|c|c|c|c|}
\hline Type Of Media & Time & $\mathbf{N}$ & $\begin{array}{l}\text { Mean } \\
\text { FP*** }\end{array}$ & $\begin{array}{c}\% \text { of } \\
\text { FD }\end{array}$ & SE & Min. & Max. & $\begin{array}{c}\text { Duncan's } \\
\text { Groups*** }\end{array}$ \\
\hline Dry & o Hour & 10 & 201.70 & $0 \%$ & 0.597 & 198 & 204 & $\mathrm{P}$ \\
\hline Dry & 1 Hour & 10 & 174.20 & $13.63 \%$ & 1.172 & 168 & 179 & $\mathrm{~N}$ \\
\hline Dry & 24 Hour & 10 & 149.20 & $26.02 \%$ & 0.854 & 145 & 154 & $\mathrm{~L}$ \\
\hline Dry & 1 Week & 10 & 126.80 & $37.13 \%$ & 0.533 & 124 & 129 & $\mathrm{~J}$ \\
\hline Dry & 3 Weeks & 10 & 117.30 & $41.84 \%$ & 0.597 & 114 & 120 & G \\
\hline Artificial Saliva & 0 Hour & 10 & 200.70 & $0 \%$ & 0.746 & 196 & 203 & $\mathrm{P}$ \\
\hline Artificial Saliva & 1 Hour & 10 & 147.90 & $26.3 \%$ & 0.737 & 145 & 151 & KL \\
\hline Artificial Saliva & 24 Hour & 10 & 111.50 & $44.44 \%$ & 0.898 & 107 & 115 & $\mathrm{H}$ \\
\hline Artificial Saliva & 1 Week & 10 & 76.10 & $62.08 \%$ & 0.690 & 73 & 80 & $\mathrm{D}$ \\
\hline Artificial Saliva & 3 Weeks & 10 & 63.80 & $68.21 \%$ & 0.800 & 59 & 68 & B \\
\hline Distill Water & o Hour & 10 & 200.40 & $0 \%$ & 0.653 & 196 & 203 & $\mathrm{P}$ \\
\hline Distill Water & 1 Hour & 10 & 153.80 & $23.25 \%$ & 0.952 & 149 & 159 & M \\
\hline Distill Water & 24 Hour & 10 & 121.30 & $39.47 \%$ & 0.803 & 118 & 126 & $\mathrm{H}$ \\
\hline Distill Water & 1 Week & 10 & 91.20 & $54.49 \%$ & 0.593 & 88 & 94 & $\mathrm{E}$ \\
\hline Distill Water & 3 Weeks & 10 & 79.70 & $60.22 \%$ & 0.597 & 77 & 82 & $\mathrm{C}$ \\
\hline Biofresh m. w. & 0 Hour & 10 & 200.20 & $0 \%$ & 0.573 & 197 & 203 & $\mathrm{O}$ \\
\hline Biofresh m.w. & 1 Hour & 10 & 147.00 & $26.57 \%$ & 0.830 & 143 & 151 & K \\
\hline Biofresh m. w. & 24 Hour & 10 & 108.70 & $45.7 \%$ & 0.684 & 105 & 113 & F \\
\hline Biofresh m. w. & 1 Week & 10 & 70.90 & $64.58 \%$ & 0.567 & 69 & 74 & $\mathrm{C}$ \\
\hline Biofresh m. w. & 3 Weeks & 10 & 60.20 & $69.93 \%$ & 0.593 & 57 & 63 & A \\
\hline
\end{tabular}

* Methods used for initial force determination. **The mean was in grams measurement, *** Different letters mean significant different at $p \leq 0.005 . \quad \mathrm{m}$. W. $=$ mouth wash 
Table (2): One - Way ANOVA Analysis For Amount Of Force Production Of Elastic Chain In all Incubation Media And At four Immersion Periods.

\begin{tabular}{ccccccc}
\hline Media & & SS & DF & MS & F-test & Sig. \\
\hline \multirow{2}{*}{ Dry } & Between Groups & 47929.72 & 3 & 11982.430 & & \\
& Within Groups & 279.000 & 45 & 6.200 & 1932.65 & $<0.001$ \\
& Total & 48208.72 & 49 & & & \\
Artificial & Between Groups & 124488.0 & 3 & 31122.000 & & \\
Saliva & Within Groups & 272.000 & 45 & 6.044 & 5148.860 & $<0.001$ \\
& Total & 124760 & 49 & & & \\
Distall Wa- & Between Groups & 117277.080 & 3 & & & \\
ter & Within Groups & 245.000 & 45 & 29319.270 & 5385.172 & $<0.001$ \\
& Total & 117522.080 & 49 & 5.444 & & \\
Biofresh & Between Groups & 132417.8 & 3 & 33104.450 & & \\
mouth wash & Within Groups & 194.200 & 45 & 4.316 & 7670.959 & $<0.001$ \\
'F' & Total & 132612.0 & 49 & & & \\
\hline
\end{tabular}

SS: sum of squares, Df: Degree of freedom, MS: Mean square

\section{CONCLUSIONS}

The elastomeric chains are greatly affected by stretching, moisture and time; exhibit rapid force loss comparing with dry condition, and the biofresh mouth wash cause more force degradation than in artificial saliva.

\section{REFRENCES}

1. Al-Ghazi HA. Mechanical behaviour and clinical efficiency of elastomeric chain and nickel titanium closed coil spring (a comparative study). M.Sc.Thesis, collage of dentistry, University of Baghdad 2001.

2. Andreasen GF, Bishara S. Comparison of alastik chains with elastics involved with intra-arch molar forces. Angle Orthod 1970; 40: 151-8.

3. Angolkar PV, Arnold JV, Nanda RS and Duncanson MG Force degradation of closed coil springs: An in vitro evaluation. Am J Ortho Dentofac Orthop; 1992; 102(2): 127-133.

4. Ash JL, Nikolai RJ. Relaxation of orthodontic elastomeric chains and modules in vitro and in vivo. J Dent Res. 1978; 57: 685-90.

5. Barrie WJ, Spence JA. Elastics their properties and clinical applications in orthodontic fixed appliance therapy. Brit $J$ Orthod. 1973; 1: 167-71.

6. Baty DL, Storie DJ, Von Frounhofer JA Synthetic elastomeric chains: A literature review. Am J Ortho Dentofac Orthop; 1994; 105(6): 536-542.

7. Baty DL, Volz JE, von Frounhofer JA Force delivery properties of colored elastomeric modules. Am. J. Ortho. Dentofac Orthop; (1994) 106(1): 40-46.

8. Bennett JC and McLaughlin RP Controlled space closure with a preadjusted appliance system. J Clin Orthod.; 1990; 24(4): 251-260.

9. Berbady THM, Adam GA. Modern chemistry of macromolecules. 1st ed., Univ. of Mosul 1989.

10. Billmeyer FW. Textbook of polymer science. 3rd ed. New York, John Wiley and Sons, 1984.

11. Bishara SE, Andreasen GF. A comparison of time related forces between plastic alastiks and latex elastics. Angle Orthod 1970; 40: 319-28.

12. Bousquet JA, Tuesta O, Flores-Mir C In vivo comparison of force decay between injection molded and die-cut stamped elas- 
tomers. Am. J. Ortho. Dentofac Orthop.; 2006;129(3): 384-389.

13. Brantley WA, Eliades $T$ and Litksy AS Mechanics and mechanical testing of orthodontic materials. In: Brantley WA, Eliades $\mathrm{T}$ (eds), orthodontic materials, scientific and clinical aspects, Thieme, Stuttgart; 2001; pp 27-49. [Cited by Eliades T, Eliades G, Silikas N and Watts DC 2004; Tensile properties of orthodontic elastomeric chains. Europ J orthod; 26: 157-162].

14. Casaccia GR, Gomes JC, Alviano DS, Ruellas AC and Anna EF Microbiological evaluation of elastomeric chains. Angle Orthod; 2007;77(5): 890-893.

15. DeGenova DC, Ledoux PM, Weinberg R and Shaye $\mathrm{R}$ Force degradation of orthodontic elastomeric chains-A product comparison study. Am J Ortho Dentofac Orthop; 1985;87(5): 377-384.

16. Eliades T, Eliades G, Silikas N and Watts D Tensile properties of orthodontic elastomeric chains. Europ J Orthod; 2004; 26 : 157-162.

17. Eliades T, Eliades G, Watts DC. Structural conformation of in vitro and in vivo aged orthodontic elastomeric modules. Eur $J$ Orthod 1999, 21(6): 649-658.

18. Evangelista MB, Berzins DW and Monaghan P Effect of disinfecting solutions on the mechanical properties of orthodontic elastomeric ligatures. Angle Orthod; 2007; 77(4): 681-687.

19. Ferriter JP, Meyers CE and Lorton L The effect of hydrogen ion concentration on the force-degradation rate of orthodontic polyurethane chain elastics. Am J Ortho Dentofac Orthop; 1990; 98(5): 404- 410. received condition and after ortho dontic use. Am. J. Ortho. Dentofac Orthop; 2004; 126(3): 337 - 343.

29. Roff WJ, Scott R. Fibers, films, plastics and rubbers: Handbook of common polymers. London, Butterworths 1971.

30. Russell KA, Milne AD, Khanna RA and Lee JM In vitro assessment of the mechanical properties of latex and non-latex orthodontic elastics. Am. J. Ortho. Dentofac Orthop; 2001;120(1): 36-44.

31. Santos ACS, Tortamano A, Naccarato SRF, Rodriguez GCD and Vigoroto JW An in vitro comparison of the force decay generated by different commercially available elastomeric chains and NiTi closed
20. Graber $\mathrm{T}$ and Vannarsdall R Orthodontic current principle and techniques. 3rd Edition, the C.V. Mosby Company; 2000; pp 305- 330,803.

21. Gioka C, Zinelis S, Eliades T and Eliades G Orthodontic latex elastic, A force relaxation study. Angle Orthod. 2006; 76(3): 475-479.

22. Huget EF, Patrick KS, Nunez LJ. Observation on the elastic behavior of a synthetic orthodontic elastomer. J Dent Res. 1990; 69: 496-501.

23. Jeffries CL and Von Frunhofer JA The effect of $2 \%$ alkaline gluteraldehyde solution on the elastic properties of elastomeric chain. Angle Orthod; 1991;61(1): 2530.

24. Kim KH, Chung CH, Choy K, Lee JS and Vanarsdall RL Effect of prestretching on force degradation of synthetic elastomeric chain. Am J Ortho Dentofac Orthop; 2005;128(4): 477- 482.

25. Natterass C, Ireland AJ, Sherriff M. The effect of environmental factors on elastomeric chain and nickel titanium coil springs. Eur J Orthod. 1998; 20: 169-76.

26. Nikolai RJ. Material behavior of the orthodontic appliance bioengineering analysis of orthodontic mechanics. 1st ed., Lee and Febiger, Philadelphia 1985; PP 245.

27. Proffit WR Contemporary orthodontics. 2nd ed. St. Louis, Mosby-Yearbook 1993; PP 145.

28. Renich MR, Brantley WA, Beck M, Vig KWL and Webb CS Studies of orthodontic elastomeric module. Part 1: Glass transition temperature for representative pigmented products in the ascoil springs. Braz Oral Res; 2007; 21(1): 51-57.

32. Staggers JN and Germane N Clinical considerations in the use of retraction mechanics. J Clin Orthod; 1991;25(6): 364369.

33. Stevenson JS and Kusy RP Force application and decay characteristics of untreated and treated polyurethane elastomeric chains. Angle Orthod; 1994;64(6): 455467.

34. Von Frounhofer JA, Coffelt MTP and Orbell GM The effect of artificial saliva and topical fluoride treatments on the degradation of the elastic properties of orthodontic chains. Angle Orthod; 1992; 
62(4):265- 274.

35. Wong AK Orthodontic elastic materials. Angle Orthod; 1976; 46(2): 196-205.

36. Shaw WC, Addy M, Griffiths S, Price C.
Chlorhexidine and traumatic ulcers in orthodontic patients. Eur J Orthod. 1984; 6: 137-140. 